\title{
A CONTRIBUIÇÃO DA PSICOLOGIA NO PROCESSO DE PSICOLOGIA NO PROCESSO DE CRIANÇAS COM SÍNDROME DE DOWN
}

\section{ARTIGO ORIGINAL}

LEITE, Madson Márcio de Farias ${ }^{1}$

MONT'ALVERNE, Clara Roseane da Silva Azevedo ${ }^{2}$

LEITE, Madson Márcio de Farias. MONT'ALVERNE, Clara Roseane da Silva Azevedo. A contribuição da psicologia no processo de inclusão escolar de crianças com Síndrome de Down. Revista Científica Multidisciplinar Núcleo do Conhecimento. Ano 05, Ed. 09, Vol. 09, pp. 05-22. Setembro de 2020. ISSN: 24480959, Link de

acesso: https://www.nucleodoconhecimento.com.br/psicologia/psicologia-noprocesso

\section{RESUMO}

Esta pesquisa objetiva investigar qual a contribuição da Psicologia no processo de inclusão escolar de crianças com síndrome de down. A inclusão de crianças com síndrome de down, no contexto do ambiente escolar, ainda é carregado de estereótipos, tanto por parte da família que, muitas vezes, não sabe dos direitos de pessoas com essa deficiência, quanto pelo tratamento dado a elas. Ademais, a falta de preparo da escola ao lidar com questões relacionadas à inclusão dessas crianças com síndrome de down no espaço educacional. A inclusão é uma prática eficaz na

${ }^{1}$ Doutorando em Ciências da Educação pela Universidade Autônoma de Assunção UAA - Py. Psicólogo e Professor de Educação Física.

2 Doutora em Ciências da Educação pela Universidade Autônoma de Assunção - UAA - Py. Assistente Social e Pedagoga da Secretaria Executiva de Educação do Estado do Pará-SEDUC. Pedagoga da Coordenação da Educação Especial - COEES. 
existência das crianças, principalmente no que diz respeito à inserção no ambiente escolar, uma vez que é através da educação que essas crianças serão capazes de almejar à liberdade, à emancipação e à autossuficiência. A metodologia utilizada foi a pesquisa bibliográfica, em que pôde ser feita uma revisão da literatura que aborda a temática da contribuição da Psicologia no processo de inclusão escolar de crianças com síndrome de down. A leitura e discussão de tais informações pretendem demonstrar a contribuição da psicologia para o processo de inclusão das crianças com síndrome de down, assim como a importância no desenvolvimento. A partir da análise bibliográfica, esta pesquisa concluiu que a Psicologia desempenha um papel imprescindível no processo de inclusão de crianças com síndrome de down no processo de inclusão escolar, o que significa proporcioná-las ferramentas e formatos de possibilidades de trabalho educacional, bem como ajudar crianças com essa necessidade especial a buscarem formas de integração nos contextos escolar, familiar e comunitário, além de prepará-las para os conflitos fora do ambiente escolar. Sendo assim, a psicologia proporciona, no ambiente escolar, base de informação e de fortalecimento para que as crianças com a síndrome de down estejam preparadas no enfrentamento dos desafios internos e externos ao ambiente escolar.

Palavras- chave: Psicologia, síndrome de down, escola, inclusão.

\section{INTRODUÇÃO}

A elaboração desta pesquisa se deu pela busca de novos conhecimentos no que se refere à contribuição da Psicologia no processo de inclusão escolar de crianças com síndrome de down, (SD). Tal escolha deve-se ao entendimento de que o assunto, mesmo sendo comum nos dias atuais, ainda é pouco efetivado no que se refere a sua prática.

Hodiernamente, a inclusão tem sido apontada como uma possibilidade de participação plena em sociedade para todos aqueles que são acometidos pela SD. A Psicologia, nesse sentido, seria uma das alternativas utilizadas para a diminuição da estigmatização e preconceitos por uma grande parcela da população, assim como para a busca da igualdade e equidade que deve ser ofertada a todos aqueles que 
tenham a referida síndrome. Dessa forma, consideramos a importância de abordar conhecimentos da Psicologia, o que contribui, em parceria com as escolas, com as técnicas de inclusão, a fim de expandir a visão e a percepção dessa condição que é comum em grande parcela da população.

O papel desempenhado pelos psicólogos dentro das escolas, com o auxílio da sociedade e da família, junto às crianças com a SD, expande-se, uma vez que grande parte das pessoas deixa de apontar e quantificar o grau de desvio dessas crianças e procura formas que permitam o crescimento e uma melhor autonomia desses indivíduos, como também permitir com que alcancem sua independência pessoal.

Diante o exposto, o objetivo dessa pesquisa foi investigar qual é a contribuição da Psicologia no processo de inclusão escolar de crianças com SD, e buscar ressaltar como essa ciência contribui para o processo de inclusão. A Educação é descrita como formadora e transformadora da mudança social dos sujeitos, de modo que pode contribuir de forma satisfatória para a vida de indivíduos com necessidades especiais, já que, sem a educação, o dinamismo da mudança será comprometido.

A esse respeito, Freire (1979) descreve, em uma de suas ideias, a importância da educação como recurso de transformação, o que revela os valores do autor. É válido ressaltar que, conforme Freire (1979), é através do conhecimento que o ser humano é capaz de buscar e lutar por ideais, bem como ascender a melhores condições de vida, numa constante luta por direitos até antes desconhecidos. Isso significa que a educação é capaz de modelar e proporcionar aos sujeitos uma independência que, muitas vezes, não se conhece.

O presente trabalho utilizou como metodologia a pesquisa bibliográfica, em que pôde ser feita uma revisão da literatura que aborda a temática da contribuição da Psicologia no processo de inclusão escolar de crianças com SD. Buscou-se enfatizar qual a contribuição dada pela Psicologia dentro dos espaços escolares, a qual é essencial para o processo da inclusão de crianças com SD. 
A relevância da pesquisa é descrita pelo fato de que o assunto é pouco realizado no contexto educacional, principalmente em estudos que enfatizam a necessidade desse profissional na vida dessas crianças. Tais estudos, quando abordam a temática, não privilegiam os diversos fatores que agregam na vida de forma integral de todos aqueles que apresentem alguma deficiência. Dessa forma, enfatiza-se a relevância deste estudo, visto ser de essencial contribuição o conhecimento ofertado por esses profissionais.

Nota-se que a escola se torna fundamental durante esse processo de inclusão, pois quando as crianças com a SD são percebidas, tratadas e ensinadas com igualdade todo o processo de aceitação no meio escolar acaba sendo favorecido, adicionando à vida delas maiores habilidades e conhecimentos, mesmo que em algumas essa aquisição seja de forma mais gradativa.

Ademais, a compreensão da referida temática é fundamental para diversas pesquisas que surgem em colaboração ao processo de inclusão, buscando assim a concretização de maiores viabilizações, de modo a promover, cada vez mais, a inserção de crianças com SD nos diversos espaços sociais, principalmente nos âmbitos escolares.

\section{DESENVOLVIMENTO}

\section{A PSICOLOGIA COMO ALIADA AO PROCESSO DE INCLUSÃO}

A concretização dos princípios inclusivistas está vinculada à participação de diversos setores sociais, como no âmbito político, econômico, educacional, familiar, cultural, saúde, entre outros. Nesse sentido, são necessárias atuações de profissionais diversos, de áreas distintas, solicitados a refletirem, debaterem e apresentarem novas ações que promovam a inclusão de todos aqueles que necessitem do processo inclusivo.

A Psicologia configura-se como uma das profissões que podem contribuir para a inserção de todos aqueles que possuem alguma deficiência, o que implica a atuação 
dessa ciência em diversos setores e contextos da sociedade. Além disso, a Psicologia proporciona instrumentos e técnicas favoráveis ao processo inclusivo, como também favorece a todos aqueles que, de alguma forma, estão à mercê de uma sociedade carregada de convencionalismos que têm se desdobrado ao longo de décadas.

A contribuição pertinente à Psicologia deve-se ao seu corpo de conhecimentos e procedimentos pertinentes a métodos de ensino, aprendizagem, desenvolvimento humano, afetividade, relações grupais e familiares, entre outros. Desse modo, o psicólogo deve buscar aliar tais temáticas aos preceitos da inclusão, visando a um trabalho interdisciplinar com outros profissionais. Contudo, é comum encontrar situações em que o psicólogo sinta dificuldades em trabalhar dessa forma.

Conforme observa Amiralian (1997), determinados profissionais de Psicologia, quando se deparam com atendimento a pessoas com deficiência, sentem-se inseguros, o que significa que eles não conseguem efetivar o atendimento, uma vez que há hesitação durante o processo. A autora elenca três questões a respeito das dúvidas levantadas por psicólogos: a intervenção terapeuta aplicada aos pacientes com necessidades especiais; se esses indivíduos são iguais aos sujeitos sem deficiência; quais as particularidades existem nesse atendimento e se esse atendimento exige posicionamento a métodos específicos para a observação.

O atendimento prestado às pessoas com deficiência, em sua grande maioria, não é diferente do que é ofertado a pessoas sem nenhuma especificidade. Porém, nesse atendimento há divergências quanto à relação a técnicas para a busca dos objetivos elencados durante a coleta de dados, já que esses pacientes necessitam de auxílio em algumas áreas específicas, o que demonstra necessidade de algumas intervenções com maiores especificidades.

Amiralian (1997) esclarece que:

Em qualquer processo interacional, seja na relação professor e aluno ou (sic) na relação terapeuta e cliente, devemos ter em mente que a condição de deficiência interfere tanto no sujeito que a possui quanto no profissional que 0 atende. Para os profissionais que atendem pessoas com deficiência, esta os afeta em vários níveis: na percepção do objeto, 
no campo do conhecimento, na área das emoções e afetos e no nível das fantasias inconscientes (AMIRALIAN, 1997, p. 33).

O processo interacional entre ambas as partes se torna um fator determinante durante o atendimento, o que pode auxiliar ou ocasionar um retrocesso ao processo. É importante ressaltar que o método interacional pode levar a vários conflitos, os quais, em grande parte, impedem o processo de desenvolvimento. Desse modo, faz-se necessário que tanto na relação existente entre professor e aluno quanto na relação terapeuta e cliente é fundamental a existência do afeto e interesse mútuo para que o processo possa fluir e obter o êxito esperado para o procedimento inclusivo.

A deficiência não pode ser vista nem entendida como apenas excitações psíquicas. Ela deve ser percebida como uma condição que ocasiona certas limitações e problemas que podem levar a certos empecilhos nas relações sociais. Embora a deficiência imponha condições especificas relacionada à condição orgânica, as necessidades básicas vivenciadas por uma pessoa com deficiência, podem ser vivenciadas e sentidas por todos aqueles sem deficiência.

Portanto, a relação existente entre paciente e terapeuta é fundamental para o bom desenvolvimento do processo, bem como para a aquisição de bons resultados, de modo que essa relação proporciona uma maior aceitação do profissional por parte dos pacientes atendidos. Dessa forma, as relações intersubjetivas realizadas durante o processo proporcionam segurança para que eles possam desenvolver habilidades e relações fora da sua área de conforto, obtendo os resultados esperados no processo terapêutico.

Para Amiralian (1997), uma relação é descrita como satisfatória para ambas as partes quando proporciona bons resultados tanto para o terapeuta quanto para o paciente com deficiência. $O$ autor, ao afirmar que uma relação satisfatória é aquela que proporciona bons resultados, refere-se à importância da qualidade das relações intersubjetivas. Ele pressupõe duas condições básicas e fundamentais: a primeira é que "a compreensão das vicissitudes causadas pela deficiência no desenvolvimento e ajustamento da pessoa dela portadora; a segunda, é que a atitude do profissional que atende essa pessoa" (AMIRALIAN, 1997, p. 36). 
Assim, deve ser ofertado um atendimento que implique benefícios à vida dessas crianças, isso quando esse atendimento é prestado de forma condizente tanto com os déficits apresentados por esse sujeito quanto pela adequação através de técnicas. Nesse ínterim, trata-se do melhor a ser disponibilizado no que se refere à qualidade na prestação de serviços psicológicos, o que leva a um possível encaminhamento a fim de que essas crianças possam buscar ajuda terapêutica fora do espaço escolar e dar continuidade às terapias de ajuda pessoal referentes ao processo da formação humana.

Incumbe ao psicólogo proporcionar apoio psicológico aos familiares das crianças que apresentam algum tipo de deficiência antes, durante e depois de sua inclusão no meio social e escolar. Para que de fato haja a mudança, devem fazer parte do processo de inclusão os professores e orientadores, com o fito de alcançar e saber lidar com as diferentes formas de ensinar, de receber e de atender as essas crianças, principalmente no que diz respeito ao desenvolvimento dessa inclusão com o sujeito, de modo a não haver exclusão e preconceito contra as crianças. É preciso que as crianças com SD ampliem seus processos cognitivos e tenham bons resultados relacionados ao desenvolvimento das funções psicológicas superiores por meio do uso da brincadeira, jogos, desenhos, contação de histórias, encenações, etc.

De acordo com os pressupostos descritos por Vygotsky (2007), o trabalho deve ser direcionado para que seja observado o potencial de cada um, e não especificamente a sua deficiência. O psicólogo, nesse período, pode oferecer um suporte aos profissionais e familiares para ajudá-los a enxergar essa criança com SD como capaz, e ajudá-la na busca da superação de suas limitações orgânicas.

A esse respeito, Amaral (1998) explica que o papel da Psicologia é fundamental na contribuição da inclusão, dado que seus profissionais têm habilidades para fazer com que os familiares possam perceber seu papel junto à criança. $O$ profissional deve destacar aos parentes que é fundamental a inserção da pessoa com deficiência, pois somente assim ela se sentirá sujeito incluso no meio social em que participa. 


\section{ATUAÇÕES DO PSICÓLOGO NA ESCOLA: ARTICULANDO A INCLUSÃO}

Quando se ressalta a presença da criança com SD na escola, dentro de uma perspectiva inclusiva, observa-se que há múltiplas viabilidades de atuação do profissional de Psicologia. A partir dos pressupostos da abordagem sócio histórica, enfatiza-se um trabalho que conjugue professores, alunos e família, visando à aprendizagem e ao desenvolvimento do aluno.

Vygotsky (2007) ressalta a relevância da educação para a constituição do sujeito e de sua vida em sociedade, na medida em que o aprendizado proporciona maiores níveis de desenvolvimento. Quando enfatizamos as crianças com SD, essa educação não pode deixar de ser priorizada e trabalhada de forma a ajudar em sua formação.

É incongruente pensar que, pelo fato de o aluno apresentar déficits em seu desenvolvimento, ele não deva frequentar a escola. De fato, partimos da hipótese de que o ambiente escolar é peça fundamental na contribuição de seu desenvolvimento, ampliando as possibilidades de crescimento e de formação das funções psicológicas superiores.

Todavia, a inclusão escolar não se desenvolve facilmente, pois situações de preconceito e discriminação também ocorrem no âmbito escolar. Por isso, torna-se uma tarefa difícil permitir com que essas crianças possam usufruir dos mesmos espaços, direitos e aprendizagem que todas as outras crianças. É pertinente destacar que a falta de conscientização e de organização de políticas voltadas à inclusão é um empecilho no meio escolar. Tais faltas provocam repúdios e receios, visto que a deficiência, para uma grande parcela da população, ainda continua desconhecida.

Dessa forma, um dos âmbitos fundamentais para a atuação do psicólogo em relação à educação é a criação de espaços de informação, esclarecimento e conscientização sobre a educação inclusiva. Schwartzman (1999) defende que a filosofia da inclusão necessita ser entendida, divulgada e delineada devidamente, com o desígnio de 
produzir resultados adequados, a fim de que todos aqueles que busquem a inclusão encontre-a dentro dos diversos contextos escolares.

A escola tem a função formativa, portanto é ambiente propício para a aquisição de hábitos, valores e conhecimentos fundamentais para o desenvolvimento intelectual. $O$ psicólogo é um agente que mobiliza e contribui para que possa existir transformação dentro do espaço escolar, já que nesse lugar há confronto de interesses, valores, ideologias, bem como conflitos. Todavia, existe a necessidade de se gerarem mudanças na subjetividade social da instituição (ANACHE, 2009).

A inserção de profissionais de Psicologia no ambiente escolar é relevante, o que tem contribuído de várias maneiras, como o suporte aos professores em dúvidas sobre a zona de desenvolvimento proximal de seus alunos, a priorização no processo de desenvolvimento do alunado no que se refere aos períodos de maturação e formação da personalidade, como na inclusão da criança com SD dentro do ambiente escolar, dentre outras.

O lugar desse profissional dentro do contexto educacional ainda causa certa dúvida quanto ao seu papel. Antigamente o papel do psicólogo era simplesmente o de identificar as questões e dificuldades inerentes ao comportamento dos sujeitos escolares. Já o novo psicólogo educacional é chamado a uma função mais abrangente: ele precisa dar conta de um outro olhar, direcionando-o às situações didáticas e a forma como as relações professor e aluno se estabelecem no centro da relação didática institucional na sala de aula (MENEZES; ARAÚJO, 2009).

Nesse sentido, o psicólogo pode estimular os processos de reflexão e capacitar os professores, entre outros envolvidos, a construírem as suas próprias críticas no interior das escolas, sejam elas especiais ou não. Fomentar a ação colaborativa nos diferentes espaços educacionais tem se mostrado esperançoso para que se promovam processos investigativos com base nas experiências advindas do processo de escolarização (ANACHE, 2009). 
O momento de estudo ao longo do processo de intervenções no espaço educacional torna-se um fenômeno crucial para a obtenção de possíveis ajustes no tocante às interferências e capacitações realizadas. É dessa forma que se podem garantir os objetivos propostos pela educação inclusiva.

A perspectiva histórico-cultural tem fundamentado as diversas críticas à cultura homogeneizadora e padronizada da deficiência, orientando-nos para uma proposta educacional que atenda às especificidades dos aprendizes. Dessa maneira, busca-se acolher cada educando de acordo com suas particularidades definida pelo tipo de deficiência.

Conforme afirma (ANACHE, 2009).

Trabalhar a partir da representação do espaço de sala de aula com espaço criativo exige de educadores e psicólogos o desenvolvimento de novos conhecimentos, novas competências e muita criatividade (sic), porém, precisamente, nesse esforço de experimentação, de fracasso e de acerto (ANACHE, 2009, p. 228).

Ademais, faz-se necessário que a educação inclusiva seja construída no âmbito educacional através de suscetíveis erros e acertos durante toda a construção do processo da inclusão escolar, de modo que atenda a todos com necessidades educacionais especiais.

O compromisso do psicólogo escolar/educacional, como integrante do espaço educativo, e com a transformação do insucesso escolar que os alunos com deficiência intelectual vivenciam em sua história de escolarização, é direcionado a esses sujeitos. Tais sujeitos recebem educação de baixa qualidade, com atividades de leitura e escrita realizadas em sala de aula de forma descontextualizada e sem que a prática social seja considerada (ANACHE, 2009).

A autora ainda destaca que o desenvolvimento do indivíduo com deficiência intelectual ocorrerá mediante a satisfação de sua necessidade a partir de seu novo aprendizado. Há que se recuperar o sentido subjetivo implicado nesse processo, pois a dimensão 
psicológica é constituída por registros simbólicos e emocionais, em que a linguagem ocupa papel essencial.

Cabe ao psicólogo, em parceria com a equipe escolar, promover ambientes no qual o conhecimento seja compartilhado e estimulado aos alunos com deficiência em sua vida, já que eles expressam dificuldades na resolução de situações-problemas. Esse profissional, também com o auxílio da comunidade escolar, deve promover práticas que possam desconstruir a visão determinista de incapacidade de aprendizagem.

A intervenção do psicólogo escolar/educacional na escola pode ser encaminhada para a construção de espaços de interlocuções, entre outras vozes, bem como para dimensões do conhecimento, dado que há variados modos de mostrar, apreender, discutir e conhecer os múltiplos discursos ligados às diferentes linguagens (ANACHE, 2009).

Isso é mais um fato a favor da parceria entre professor e psicólogo no favorecimento do processo de aprendizagem das crianças que adentram o espaço educacional, sendo o profissional de Psicologia um parceiro não só no entendimento da deficiência, como também na buscar de técnicas especificas para se trabalhar as habilidades de cada estudante.

Seus esforços em atender a esse alunado deverão ter foco na redução dos déficits da criança, dando-lhe oportunidade e o tempo necessários, mas sem visar modificar as estruturas ou fatores que causam uma possível limitação ou atraso no desenvolvimento global da criança, (sic) pois esse é um campo de atuação para outros profissionais. Ao educador caberá repensar sua ação pedagógica, adaptar o currículo às necessidades do aluno, tornar o conhecimento acessível e principalmente reavaliar seu conceito de educação, de homem, de cidadania e deficiência (SILVA; TAVARES, 2009, p. 83-84).

Sob esse aspecto, o psicólogo é fundamental enquanto parceiro do professor, pois seus conhecimentos sobre aprendizagem, desenvolvimento no processo da relação professor e aluno, bem como sobre deficiência, dentre outros, podem contribuir com o docente nessa reflexão. Isso significa que o psicólogo é capacitado para tornar os conteúdos e práticas mais acessíveis ao alunado que têm alguma deficiência. 
É recorrente, no cotidiano escolar, ouvir os professores sobre suas dificuldades em lidar com as diferenças na sala de aula, especialmente quanto às deficiências. Logo, o docente pode encontrar situações de atendimento a crianças com a especificidade da deficiência de SD, o qual pode alegar incapacidade, especialmente devido à falta de informação do que fazer e de como fazer referência a essa deficiência.

Entretanto, a criança com SD não se enquadra como incapaz, mas como possuidora de certa limitação com funções e capacidades a serem desenvolvidas. Faz-se necessário, então, que o professor, no contexto da sala de aula e fora dela, saiba lidar com essa diferença, o que o levaria a afirmar que crianças com deficiência são capazes de se desenvolverem intelectualmente. A dúvida e incerteza da prática conduzem à necessidade de o psicólogo realizar um trabalho com os profissionais que estão à frente da educação dessas crianças, a fim de discutir as formas de lidar com as diferenças.

Segundo Buscaglia (1993), o orientador possui a função de integrar os alunos com deficiência no contexto da sala de aula regular. No entanto, conforme o autor, para que isso ocorra, em primeiro plano, deve haver o estabelecimento de vínculo entre professor e aluno, sem demonstração de sentimento de compadecimento ou, muito menos, sentimento de superproteção. Portanto, o grande desafio está em conseguir conscientizar o educando deficiente de que ele tem suas potencialidades, estímulo esse que deve partir de toda a sociedade.

A inclusão, como destaca alguns autores, não se resume às necessidades educacionais, isto é, apenas em alocar uma criança deficiente em uma sala de aula. Vale destacar que isso significa, como afirmamos anteriormente, que não estaríamos realizando a inclusão, e sim apenas integrando essa criança na sala de aula. A esse respeito, Diniz (2008) sublinha que o potencial para a aprendizagem das crianças com SD é mais bem observado quando elas estão inseridas num programa educacional que incite o desenvolvimento de habilidades acadêmicas básicas, como também estimule aptidões físicas e independência na vida da pessoa com SD. 
Diniz (2008) considerou que um programa educacional adequado ao trabalho com a SD encontra amparo nos escritos de Vygotsky. Nesse sentido, o psicólogo, na escola, torna-se um parceiro imprescindível do educador na identificação das zonas de desenvolvimento proximais das crianças e na proposição de atividades que explorem tais zonas e que possam suscitar a abertura de novas Zona de Desenvolvimento Proximal (ZDP).

Os estudos sobre as relações entre desenvolvimento e aprendizado foram feitos por Vygotsky desde suas primeiras obras. A partir delas, o desenvolvimento humano é percebido como um processo sócio histórico. Nessa perspectiva, enfatiza-se a importância de dinamismos referentes à aprendizagem, já que, de acordo com os descritos de Vygotsky, desde o nascimento da criança o aprendizado "está relacionado ao desenvolvimento e é um aspecto necessário e universal do processo de desenvolvimento das funções psicológicas culturalmente organizadas e especificamente humanas" (OLIVEIRA, 1997, p. 57).

Neste sentido, as crianças com deficiência necessitarão constantemente da criação de novas ZDP, posto que seus níveis de desenvolvimento não devam ser medidos apenas por sua maturação biológica, tampouco pelo nível de desenvolvimento real. É Através da mediação e do aprendizado que seu desenvolvimento real pode chegar ao nível de desenvolvimento potencial, ou seja, é preciso proporcionar meios que interfiram nas ZDP, para que seu desenvolvimento transcenda ao que foi estipulado como real.

Devido à deficiência primária apresentada pelos sujeitos com SD, os autores Ferreira, Ferreira e Oliveira (2010) asseguram que o processo de desenvolvimento físico e intelectual é mais lento, se comparado às demais crianças. Todavia, alegam as autoras que o nível cognitivo das crianças dependerá de como o funcionamento psicológico delas for trabalhado e a da forma como essa criança será estimulada durante todo o seu processo de desenvolvimento.

Ao se analisar tal perspectiva, percebe-se que a mediação se torna um poderoso instrumento de favorecimento de aprendizagem quando esses alunos com SD 
passam a frequentar salas regulares de ensino com outras crianças sem a deficiência. É assim que a aquisição de novas ZDP começa a ser criada e que o aprendizado (orientado pelo professor como mediador) pode alcançar níveis satisfatórios em todas as áreas durante processo de desenvolvimento do educando.

Os professores tornam-se um instrumento de mediação, ao desencadear os processos de aprendizagem por trocas de experiências entre os sujeitos nas relações vividas em sociedade. Destarte, o aprendizado pode ser essencialmente mediado, o que torna o papel do professor mais determinante no tocante ao aprendizado. Nesse âmbito, o psicólogo pode contribuir com o trabalho pedagógico, auxiliando o docente nessas mediações.

Schwartzman (1999) ressalta a necessidade do desenvolvimento de programas que possam favorecer a criatividade e ações que incidam em melhores resultados no que se refere à qualidade de vida para essas crianças. A preparação para uma vida adulta autônoma e independente deve ser preocupação central de tais programas.

Pueschel considera que:

A boa educação oferece uma combinação de habilidades básicas e especializadas. Para proporcionar esse tipo de educação para crianças com SD, os educadores devem conhecer os desafios e problemas que essas crianças enfrentam, e (sic) como se responde a tais desafios (PUESCHEL, 1993, p. 183).

Dessa forma, faz-se pertinente que se trabalhem os procedimentos de comunicação e socialização desses sujeitos. O conhecimento do problema pode acarretar resultados satisfatórios quando se fala em crianças com SD, o que implica o fato de elas serem capazes de obterem resultados satisfatórios em todo o seu processo de desenvolvimento de forma íntegra. A partir disso, poder-se-á possibilitar o desenvolvimento da interação desses indivíduos com seus pares não deficientes, manter empregos e participar de espaços e atividades acessíveis à população não deficiente. 
Enfatiza-se, ainda, que a prática de atividades físicas na escola é fortemente recomendada por estudiosos da área, visto que a prática de esportes é uma rica fonte de interação com o outro, já que, ao mesmo tempo em que há a interação, também acontece a comunicação. Desse modo, a criança com necessidade especial adquire novas habilidades essenciais para o seu desenvolvimento.

$\mathrm{Na}$ concepção dos autores deste artigo, a educação de crianças com a SD deve transcender ao ensino da leitura, da escrita, da aritmética e dos demais processos de ensino-aprendizagem que possam ser ofertados a todos aqueles com deficiência. Urge que seja ampliado o foco de abrangência do trabalho com a cognição, como também com as emoções, sentimento e afetos. Concorda-se com Buscaglia quando ele enfatiza que "os professores de crianças deficientes podem ministrar seu currículo de línguas, ciências, matemática, estudos sociais e artes, e ao mesmo tempo trabalhar os sentimentos dos alunos" (BUSCAGLIA, 1993, p. 39).

Assim, o psicólogo que atua com o professor oportuniza a transferência do foco nas limitações e deficiência para a relação professor-aluno e para as possibilidades dessa relação. Apresentar à escola discussões sobre as relações entre aprendizagem e desenvolvimento, como também destacar qual o papel do professor como mediador de conhecimentos e qual a importância da relação entre pensamento e linguagem devem estar na agenda de trabalho do psicólogo de perspectiva inclusiva.

Além da parceria com o educador, o psicólogo, na escola, deve atentar para atuações que aprofundem os laços entre comunidade escolar e família. É preciso que esses profissionais utilizem estratégias para a participação de forma integrada da família nas ações, como também estratégias que viabilizem a vivência de seus filhos durante todo o período em que todos estejam compartilhando ativamente desse espaço.

Voivodic e Storer (2002) enfatizam a necessidade de se reconhecer o contexto escolar em que essas crianças com deficiência serão inseridas:

Por mais que a escola e os profissionais se esforcem no sentido de promover o desenvolvimento da criança com deficiência no caso da SD, seus esforços serão bastante limitados se não incluírem, tanto em sua 
filosofia educacional quanto em sua prática de ação, uma orientação aos pais (VOIVODIC e STORER, 2002, p. 38).

É preciso resgatar, na família, o papel de protagonistas de primeira instituição de educação, ressaltando sua importância na participação ativa do desenvolvimento da aprendizagem de seus filhos. Uma vez que o contato inicial como algumas regras e conceitos é feito primeiro por seus familiares, o processo educacional surge após toda essa base, a qual faz todo o diferencial na vida dos sujeitos com deficiência.

O profissional de Psicologia surge como apoio durante o processo de inserção no contexto educacional e possibilita ajuda em diversos anseios demonstrados pela família e pelas crianças, as quais, em considerável parte, não obtiveram o apoio necessário no contexto familiar.

\section{CONSIDERAÇÕES FINAIS}

A inclusão apresenta-se como um divisor de águas no universo da consolidação dos direitos das pessoas com deficiência. No entanto, a execução dessa integração ainda acontece a passos lentos no tocante à prática efetiva nos vários contextos sociais em que e as crianças com SD estão presentes. Dessa forma, negligenciam-se direitos básicos a essa minoria.

De fato, o exercício da inclusão cumpre-se de forma mais frequente em diversas partes do mundo, mesmo que vários lugares ainda necessitem de políticas públicas peculiares para a ocorrência, de fato, do desenvolvimento da criança com essa síndrome. Desse modo, os desafios que precisam ser superados são enormes, dentre eles a falta de conhecimento inerente a uma grande parcela da população, a alguns profissionais e ao desconhecimento da importância da família durante a inclusão.

A ciência tem buscado oportunizar, através das informações e das publicações, uma maior visibilidade dos sujeitos com deficiência, a fim de que a população em geral compreenda que aquele que tem alguma deficiência pode desenvolver-se. Não se pretende, com essa afirmação, negar o fato de que o desenvolvimento da criança com SD possa ser mais lento. Será através do suporte dado por profissionais, dentre os 
quais se destaca o psicólogo, e da relação entre família e a criança com deficiência que desafios serão superados, já que ela é capaz de desenvolver suas potencialidades. Cabe, além disso, não colaborar para a existência de nenhum tipo de prejulgamento que foi direcionado por vários períodos por uma grande parcela da população.

Durante séculos pessoas que possuíam alguma necessidade especial eram rotuladas, condenadas e marginalizadas à própria sorte e à morte. Isso acontecia porque não havia equidade entre pessoas consideradas "normais" e pessoas consideradas “anormais". No entanto, esse cenário, no século XXI, está sendo reestruturado e tem ganhado uma nova visão, a qual é cada vez mais distante do que era a percepção e tratamento oferecido às pessoas com deficiência em décadas passadas. Dessarte, a luta é para que todos possam viver e crescer dentro de uma sociedade de forma igualitária, efetivando o que já é previsto em lei.

Quando se refere aos direitos dos indivíduos com deficiência em vários espaços nos quais eles transitem, esses direitos acabam nem sempre são reconhecidos e, por isso, a importância de profissionais dedicados para proporcionar e fazer valer tais determinações e os princípios inclusivistas que estão enfatizados nas leis e decretos que asseguram direitos e garantias fundamentais a todos aqueles que possuem alguma deficiência.

É por meio da educação que se torna possível a formação de pessoas mais críticas e conhecedores de seus direitos e deveres, uma vez que o aprendizado propiciado pela educação é capaz de moldar o ser humano de forma a torná-lo um ser mais racional e comprometido com a mudança social. Ademais, ao formar sujeitos conhecedores de causa, será permitido que pessoas com a SD possam exigir o cumprimento de seus direitos.

O exercício da docência é de extrema importância durante todo o desdobramento da aprendizagem de crianças com SD, uma vez que professor formará um elo entre o conhecimento e o aluno, permitindo que esse sujeito possa, através do 
compartilhamento de informações, formar-se um ser educado e capaz de mudar a situação social na qual viva.

Todavia, o papel desempenhado pelo profissional de Psicologia dentro do espaço escolar é de fundamental contribuição para a formação e capacitação de todos aqueles que fazem parte do contexto educacional, principalmente dos docentes. Isso porque, para que sejam ofertadas formações, toda a comunidade escolar possa adquirir habilidades para lidar com as diferenças, como também permitir melhorias durante o desenvolvimento dessas crianças, principalmente no que se refere aos aspectos da aprendizagem desses sujeitos.

Tendo em vista o que foi exposto, nota-se que os psicólogos são essenciais para a busca de metodologias que sejam viáveis à inclusão escolar de crianças com SD, já que elas possuem ferramentais que podem possibilitar uma melhoria no ambiente escolar. Além disso, esses profissionais podem favorecer os aspectos ligados não apenas ao aprendizado, mas à formação da personalidade desses sujeitos quando eles ingressam no ambiente educacional. Sendo assim, esse profissional surge como um facilitador na contribuição desse longo processo de aceitação e desmistificação da deficiência.

\section{REFERÊNCIAS}

AMARAL, Lígia Assumpção. Sobre crocodilos e avestruzes: falando de diferenças físicas, preconceitos e sua superação. In: AQUINO, Julio Groppa (org.). Diferenças e preconceitos na escola: alternativas teóricas e práticas. São Paulo: Summus, 1998.

AMIRALIAN, Maria Lúcia T. M. O psicólogo e a pessoa com deficiência. In: Becker, Elisabeth et. al. Deficiência: alternativas de intervenção. São Paulo: Casa do Psicólogo,1997.

ANACHE, A. A. O psicólogo escolar e o processo de escolarização de pessoas com deficiência intelectual. In: MARINHO-ARAÚJO, C. M. Psicologia escolar: novos 
cenários e contextos de pesquisa, formação e prática. Campinas-SP: Editora Alínea, 2009.

BUSCAGLIA, Leo. Os deficientes e seus pais. 5. ed. Rio de Janeiro: Record, 1993.

DINIZ, Adriana C. D. O processo de inclusão da criança com Síndrome de Down em contextos escolares diferenciados. 2008. 113f. Dissertação (Mestrado em Educação e Sociedade) - Programa de Pós-Graduação em Educação e Sociedade da Universidade Presidente Antônio Carlos, Barbacena, 2008.

FERREIRA, Diana R. S. A; FERREIRA, Wímory A; OLIVEIRA, Marinalva S. Pensamento e linguagem em crianças com síndrome de Down: um estudo de caso da concepção das professoras. Ciências \& Cognição. 2010; Vol 15 (2): 216-227.

FREIRE, P. Educação e mudança. Rio de Janeiro: Paz e Terra (1979).

MENEZES, Anna P. A. B; ARAÚJO, Cláudia R. Redescobrindo a teoria psicogenética à luz da psicologia educacional: contribuições e possíveis desdobramentos. In: CORREIA, Mônica (Org.). Psicologia e escola: uma parceria necessária. Campinas-SP: Editora Alínea, 2009.

OLIVEIRA, Marta Kohl. Vygotsky aprendizado e desenvolvimento: um processo sócio-histórico, São Paulo: Scipione, 1997.

PUESCHEL, Siegfried M. Síndrome de Down: guia para educadores. Campinas, SP: Papirus, 1993.

SCHWARTZMAN, José Salomão. Síndrome de Down. São Paulo: Mackenzie: Memnon, 1999.

SILVA, Jaqueline; TAVARES, Helenice M. A atuação pedagógica docente na inclusão de crianças com deficiência no ensino fundamental. Revista da Católica, Uberlândia, v. 1, n. 1, p. 70-86, 2009. 
VOIVODIC, Maria A.; STORE, Márcia R. S. O desenvolvimento cognitivo das crianças com Síndrome de Down à luz das relações familiares. Psicologia: teoria e prática, 2002, 4(2): 31-40.

VYGOTSKY, Lev S. A formação social da mente: o desenvolvimento dos processos psicológicos superiores. 7. ed. São Paulo: Martins Fontes, 2007.

Enviado: Junho, 2020.

Aprovado: Setembro, 2020. 